\section{(A) OPEN ACCESS}

\title{
Income-related inequality in health and health-related behaviour: exploring the equalisation hypothesis
}

\author{
Laura Vallejo-Torres, ${ }^{1,2,3}$ Daniel Hale, ${ }^{4}$ Stephen Morris, ${ }^{1}$ Russell M Viner ${ }^{4}$
}

\begin{abstract}
- Additional material is published online only. To view please visit the journal online (http://dx.doi.org/10.1136/jech2013-203306).

1 Department of Applied Health Research, University College London, London, UK

${ }^{2}$ Center for Biomedical Research of the Canary Islands (CIBICAN), Universidad de la Laguna, Tenerife, Spain

${ }^{3}$ Departamento de Economía de las Instituciones, Estadística Económica y Econometría, Universidad de la Laguna, Tenerife, Spain

${ }^{4}$ UCL Institute of Child Health, University College London, London, UK
\end{abstract}

\section{Correspondence to} Dr Laura Valllejo-Torres, Universidad de la Laguna, Campus Guajara s/n, 38320 San Cristóbal de la Laguna, Canary Islands, Spain; laura.vallejotorres@sescs.es

Received 27 August 2013 Revised 21 January 2014 Accepted 6 February 2014 Published Online First 11 March 2014
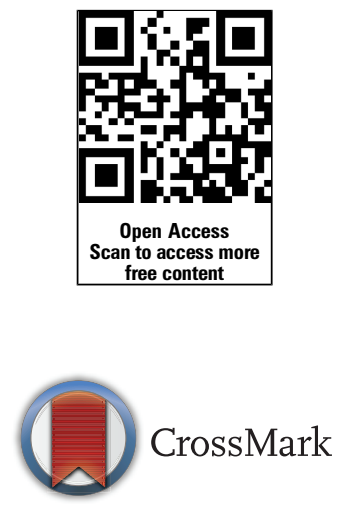

To cite: Vallejo-Torres $L$, Hale D, Morris S, et al. J Epidemiol Community Health 2014;68:615-621.

\begin{abstract}
Background Previous studies have found the socioeconomic gradient in health among adolescents to be lower than that observed during childhood and adulthood. The aim of this study was to examine income-related inequalities in health and health-related behaviour across the lifespan in England to explore 'equalisation' in adolescence.
\end{abstract}

Methods We used five years of data (2006-2010) from the Health Survey for England to explore inequalities in six indicators: self-assessed general health, longstanding illness, limiting longstanding illness, psychosocial wellbeing, obesity and smoking status. We ran separate analyses by age/gender groups. Inequality was measured using concentration indices.

Results Our findings for longstanding illnesses, psychosocial wellbeing and obesity were consistent with the equalisation hypothesis. For these indicators, the extent of income-related inequality was lower among late adolescents (16-19 years) and young adults (20-24 years) compared to children and young adolescents (under 15 years), mid- and late-adults (25-44 and 45-64 years) and the elderly (65+ years). The remaining indicators showed lower inequality among adolescents compared to adults, but higher inequality when compared with children.

Conclusions Our work shows that inequalities occur across the life-course but that for some health issues there may be a period of equalisation in late adolescence and early adulthood.

\section{INTRODUCTION}

Within the UK and internationally, there is a clear social gradient for health. There is evidence for poorer health in countries with relatively low national wealth, ${ }^{1}$ and high rates of income inequality within countries is associated with lower national health. ${ }^{2}$ The burden of poor health is, in most contexts, found to fall disproportionately on those with lower socioeconomic status (SES). ${ }^{3}$

Despite evidence of pervasive health inequalities across the lifespan, it has been suggested, that compared with childhood and adulthood, adolescence is a period of relative health equality. ${ }^{4}$ Studies provide evidence for attenuation of inequalities in adolescence for outcomes, such as all-cause mortality, mental health, disability, health conditions and general health. ${ }^{2}{ }^{5-10}$ Others have contested this, showing that social gradients can be seen across a range of health behaviours and outcomes in adolescents in many countries. ${ }^{2} 11$

Several explanations for a reduction in health inequalities during adolescence have been postulated, mainly focusing on the increase of school and peer influences relative to home and family effects on health. ${ }^{9}$ In most countries, schools are sociodemographically heterogeneous allowing for 'social mixing' across SES which may dilute the effects of SES on health. Furthermore, schools offer a set of health-promoting resources available across the socioeconomic spectrum, including knowledge, skills, access to health professionals and physical activity. Adolescence is associated with increasing independence and autonomy, ${ }^{2}$ and also with an increased propensity for risky behaviours across the social spectrum. ${ }^{12}$ For substance use, peer group identification, though itself associated with SES, is a stronger predictor of risky behaviour than parental SES. ${ }^{13}$

The existing literature has investigated the equalisation hypothesis by examining social gradients in health outcomes at different time-points throughout adolescence or by interpreting age by SES interaction effects on health outcomes. However, we are aware of no published attempts to systematically examine change in inequalities across a wide range of ages.

We aimed to contribute to the understanding of health inequalities across the life-course by examining health inequalities in discrete age groups from birth to old age. In particular, we examine the socioeconomic-related health inequalities from childhood through adolescence into adulthood. This allows us to investigate equalisation in health during adolescence.

\section{METHODS}

\section{Data}

The analysis was based on data from five yearly rounds (2006-2010) of the Health Survey for England (HSE). The HSE is a cross-sectional representative national survey that draws an annual sample of individuals living in England. We ran separate analyses in childhood (0-11 years), early adolescence (12-15 years), late adolescence (16-19 years), early adulthood (20-24 years), midadulthood (25-44 years), late adulthood (45-64 years), and the elderly (aged 65 years and above). Childhood and adolescence age groups were defined using WHO-endorsed classifications. ${ }^{14}$ To allow for finer-grained analyses within adolescence, we created a distinction between early and late adolescence at the midpoint of the adolescent period. To reflect growing empirical evidence for a qualitatively distinct period of 'emerging adulthood' ${ }^{15}$ we created a separate age group for young adults. Adulthood, similar to adolescence, was divided at 
the midpoint, with elderly respondents defined based on the widely accepted cut-point of 65 years. ${ }^{16}$ Pooling observations, data were available for 64699 individuals.

\section{Health and health-related behaviour}

We explored income-related inequality in a range of indicators of health and health-related behaviour. The indicators were selected a priori based on the variables for which information was available in a comparable form across the life-course in a number of survey years. The following outcomes were analysed: self-assessed general health, presence of longstanding illnesses, presence of a limiting longstanding illness, psychosocial wellbeing, obesity and smoking status. Information on these indicators was self-reported with the exception of height and weight data which were measured by the interviewer and used to indicate obesity. Responses for children aged 0-12 years were parent-reported, with the exception of smoking status for children aged 8 years and above which was based on self-report.

All indicators were defined as binary variables. Self-assessed health was transformed into a binary variable taking the value 1 if the respondent reported to be in fair, bad or very bad health, and 0 otherwise. We also conducted a sensitivity analysis where the variable took the value 1 in those reporting bad and very bad health only, and 0 otherwise. The results were consistent, but the second specification led to some age categories with fewer than $1 \%$ of cases reporting poor health; therefore, we focused on the first definition. Psychosocial wellbeing was defined using the Strengths and Difficulties Questionnaire (SDQ) for children aged 4-15 years, ${ }^{17}$ and the General Health Questionnaire (GHQ-12) for individuals aged 16 years and above. ${ }^{18}$ We created a binary variable taking the value 1 when the overall score for these questionnaires was above published thresholds for psychological distress, that is, 17 and above for SDQ, and 4 and above for GHQ-12, and 0 otherwise. We explored the impact of varying these cut-off points and found very similar results when they were defined as 14 and above for the SDQ and 3 and above for the GHQ-12. Obesity was defined in terms of Body Mass Index (BMI), measured as weight in kilogrammes divided by height in metres squared $(\mathrm{kg} /$ $\mathrm{m}^{2}$ ). Obesity among individuals aged 18 years and above was defined as BMI $>30 \mathrm{~kg} / \mathrm{m}^{2}$. Individuals aged 2-17 years were classified as obese if their BMI was higher than the International Obesity Task Force (IOTF) cut-offs for obesity, which vary by age and gender. ${ }^{19}$ We also classified those under 18 years as obese if their BMI was in the highest 5\% of values for boys or girls of their age based on the 1990 UK BMI reference data, ${ }^{20}$ but the results were not qualitatively different so we focused on the first definition. Smoking status was defined according to whether the individual reported currently smoking cigarettes (yes $=1,0$ otherwise).

Data on general health, longstanding illnesses, limiting longstanding illnesses, obesity and smoking were available in every survey year included in this study. The SDQ was only collected in 2006 and 2008, and the GHQ-12 was included in 2006 and 2008-2010.

\section{Income}

Annual household income was specified as the log transformation of a continuous variable based on the predicted value from an interval regression of annual household income reported in 31 income bands, against a rich set of individual and household characteristics. The values were equivalised using the weights provided in the HSE to account for household composition, and transformed to 2010 prices. Around 22\% of the sample did not report their household income, and missing income values were imputed based on out-of-sample predictions from the interval regression model.

\section{Measure of inequality}

We used the health concentration index (CI) as our measure of income-related inequality. ${ }^{21} \mathrm{CIs}$ are measures of inequality, measuring inequality in one variable (eg, health status, health-related behaviour) related to the ranking of another variable (eg, income). The CI lies between -1 and +1 , and it takes a positive (negative) value when there is income-related inequality favouring the rich (poor). Technical information of the formulae of the CI is provided in the appendix A (web only file).

One advantage of CIs is that they provide the possibility of summarising the extent of inequality in a single measure that can be used to compare inequality levels across groups. However, for binary indicators, the bounds of the CI depend on the mean of the variable. To account for this we applied a correction proposed by Erreygers, ${ }^{22}$ allowing us to compare the level of inequalities between age groups, which have varying levels of mean health. These indices are referred to as corrected concentration indices (CCI).

CIs and CCIs capture the extent of the association between health and income, but they might be a misleading measure of the extent to which inequalities in health are attributable to income if there are other factors that affect health and are correlated with income. ${ }^{23}$ Therefore, we also computed the partial CI of health with respect to income, which adjusts for variables likely to be correlated with income, including: age (a cubic function); ethnic group (eight categories); area of residence (nine Government Office Regions); survey year (five categories); and whether or not income was imputed. We then applied the correction proposed by Erreygers and computed the Partial CCI (PCCI).

Based on model-selection statistics (ie, the Akaike Information Criterion (AIC) and the Bayesian Information Criterion (BIC)), probit models were found to better fit the data and were used throughout. We computed the marginal effect of income for the computation of the PCCI. Based on these models we additionally tested whether the effect of income was statistically significantly different across age groups by comparing the effect observed in each age group with that observed in the previous age group using Wald tests for testing cross-model hypotheses. ${ }^{24}$

In all analyses, we adjusted for clustering at the Primary Sampling Unit level and we used sample weights provided in the HSE. SEs around CIs were computed using the delta method. ${ }^{25}$ All analyses were stratified by gender.

All analyses were undertaken using Stata V.12. ${ }^{26}$

\section{RESULTS}

Tables 1 and 2 report summary statistics of the health and health-related behaviour indicators by age group and gender. The proportion of males reporting a negative health outcome increased with age, although young adolescents (aged 12-15 years) reported worse health outcomes than older adolescents and young adults for most health indicators. Obesity and smoking prevalence among males increased with age but dropped in late adulthood. Among females, the proportion reporting a negative health outcome increased with age, except for psychosocial wellbeing. The prevalence of obesity also increased continuously with age, while smoking was less common among older adults and the elderly compared with younger groups. 
Table 1 Summary statistics of health and health-related behaviour by age group-males

\begin{tabular}{|c|c|c|c|c|c|c|}
\hline \multirow[b]{3}{*}{ Age group (years) } & \multirow{2}{*}{\multicolumn{2}{|c|}{$\begin{array}{l}\text { General health } \\
\text { (=1 if fair, bad, very bad } \\
\text { health) }\end{array}$}} & \multicolumn{2}{|c|}{ Longstanding illnesses (LI) } & \multicolumn{2}{|c|}{ Limiting LI } \\
\hline & & & \multicolumn{2}{|c|}{ (=1 if presence of LI) } & \multicolumn{2}{|c|}{$\begin{array}{l}\text { (=1 if presence of } \\
\text { limiting LI) }\end{array}$} \\
\hline & Sample & $\%$ & Sample & $\%$ & Sample & $\%$ \\
\hline $0-11^{*}$ & 3786 & 4.7 & 3111 & 17.9 & 3111 & 6.4 \\
\hline $12-15 t$ & 1542 & 6.1 & 1281 & 21.3 & 1281 & 8.8 \\
\hline $16-19$ & 1161 & 8.7 & 968 & 18.1 & 968 & 6.9 \\
\hline $20-24$ & 1232 & 14.6 & 1043 & 19.2 & 1043 & 7.6 \\
\hline $25-44$ & 7016 & 14.9 & 5875 & 29.2 & 5875 & 13.8 \\
\hline $45-64$ & 7431 & 28.0 & 6163 & 48.7 & 6163 & 26.1 \\
\hline $65+$ & 5124 & 42.3 & 4204 & 70.2 & 4204 & 42.2 \\
\hline \multirow[t]{3}{*}{ All } & 27292 & 19.6 & 22645 & 36.2 & 22645 & 18.6 \\
\hline & \multicolumn{2}{|c|}{ Psychosocial health* } & \multicolumn{2}{|l|}{ Obesity* } & \multicolumn{2}{|c|}{ Smokingt } \\
\hline & \multicolumn{2}{|c|}{$\begin{array}{l}(=1 \text { if } S D Q \geq 17 \text { for ages } \\
4-15 \text { or if } G H Q-12 \geq 4 \text { for } \\
\text { ages } 16+)\end{array}$} & \multicolumn{2}{|c|}{$\begin{array}{l}\text { (=1 according to IOTF } \\
\text { classification for ages } 2-17 \text { or } \\
\text { if } B M I \geq 30 \text { for ages } 18+\text { ) }\end{array}$} & \multicolumn{2}{|c|}{$\begin{array}{l}\text { (=1 if currently smokes } \\
\text { for ages } 8+\text { ) }\end{array}$} \\
\hline Age group (years) & Sample & $\%$ & Sample & $\%$ & Sample & $\%$ \\
\hline $0-11^{*}$ & 1638 & 10.7 & 3074 & 6.2 & \multirow{2}{*}{2728} & \multirow{2}{*}{2.2} \\
\hline $12-15 t$ & 816 & 9.5 & 1352 & 7.4 & & \\
\hline $16-19$ & 961 & 7.9 & 1038 & 7.2 & 1073 & 19.0 \\
\hline $20-24$ & 1002 & 12.1 & 1099 & 11.0 & 1204 & 31.8 \\
\hline $25-44$ & 5799 & 11.8 & 6232 & 21.8 & 6981 & 30.9 \\
\hline $45-64$ & 6223 & 13.0 & 6522 & 32.4 & 7417 & 21.3 \\
\hline $65+$ & 4207 & 11.2 & 4191 & 27.1 & 5120 & 11.0 \\
\hline All & 20646 & 10.4 & 23508 & 21.1 & 24523 & 21.4 \\
\hline
\end{tabular}

The results of the interval regression model for income are shown in appendix B (web only file). Most of the variables were significantly associated and had the expected sign, with lower SES being negatively correlated with household income.

Table 3 presents the income-related inequality estimates for each indicator by age and gender. In most cases, worse health and health-related behaviour was concentrated among the poor, and in nearly every case the CCI was larger than the PCCI, suggesting that income was confounded by other factors in the CCI. The variation in the level of inequality between age groups was similar for the CCI and the PCCI.

For longstanding illnesses, psychosocial wellbeing, and obesity, the extent of income-related inequality was considerably lower (in absolute terms) among late adolescents and young adults compared to children, older adults and the elderly in males and females. Furthermore, the level of income-related inequality as measured by the CCI among individuals aged 1619 years and 20-24 years was not significantly different from zero in most of these indicators, while it was significant in every other age group. The extent of inequality in limiting longstanding illnesses was also lower in adolescents compared to young children and older adults, and was non-significant among males aged 16-19 years. For general health and smoking, inequality in adolescents remained significant, but it was smaller compared to that observed in older adults (though generally larger compared with children). For every health and health-related indicator, the level of inequality was lower among the elderly compared to younger adults groups, with the exception of smoking among males.

The income effect among children and young adolescents was not significantly different, but the results showed in some cases a different impact between those aged 12-15 years and those aged 16-19 (see table 3). The impact of income on health among late adolescents (aged 16-19 years) and young adults (aged 20-24 years) was not significantly different, but the impact in mid-adults (25-44 years) was significantly different to that in young adults in some instances, especially among females. Among males the income effect was not statistically significantly different until comparing 25-44 year and 45-64 year age groups for most indicators. For both genders and in almost every health indicator, the impact of income was significantly different in the elderly compared with older adults.

\section{DISCUSSION}

Our findings demonstrate that for all health indicators the burden of poor health falls disproportionately on those of lower SES at all ages. However, the magnitude of health inequalities is not consistent across age groups. The majority of health outcomes show marked inequality in childhood, and evidence of equalisation in late adolescence and early adulthood with inequality re-emerging again in mid-adulthood and late adulthood.

Our results demonstrate a period of equalisation in health inequalities that does not conform with the developmental period generally characterised as adolescence. Instead, where significant reductions of inequalities were found, they arose when comparing early adolescents (12-15 years) to late adolescents (16-19 years) and the re-emergence of inequalities was evident when comparing early adulthood (20-24 years) to older adults. 
Table 2 Summary statistics of health and health-related behaviour by age group-females

\begin{tabular}{|c|c|c|c|c|c|c|}
\hline \multirow[b]{3}{*}{ Age group (years) } & \multicolumn{2}{|c|}{ General health } & \multicolumn{2}{|c|}{ Longstanding illnesses (LI) } & \multicolumn{2}{|c|}{ Limiting LI } \\
\hline & \multicolumn{2}{|c|}{$\begin{array}{l}\text { (=1 if fair, bad, very bad } \\
\text { health) }\end{array}$} & \multicolumn{2}{|c|}{ (=1 if presence of LI) } & \multicolumn{2}{|c|}{$\begin{array}{l}\text { (=1 if presence of } \\
\text { limiting LI) }\end{array}$} \\
\hline & Sample & $\%$ & Sample & $\%$ & Sample & $\%$ \\
\hline $0-11^{*}$ & 3683 & 4.8 & 3051 & 14.9 & 3051 & 5.2 \\
\hline $12-15 t$ & 1460 & 7.4 & 1236 & 16.7 & 1236 & 7.0 \\
\hline $16-19$ & 1309 & 11.2 & 1100 & 21.0 & 1100 & 11.2 \\
\hline $20-24$ & 1544 & 16.1 & 1277 & 26.2 & 1277 & 11.6 \\
\hline $25-44$ & 9023 & 16.3 & 7506 & 30.7 & 7506 & 15.0 \\
\hline $45-64$ & 8910 & 26.9 & 7312 & 50.2 & 7312 & 28.3 \\
\hline $65+$ & 6441 & 44.4 & 5309 & 70.4 & 5309 & 46.5 \\
\hline \multirow[t]{3}{*}{ All } & 32370 & 21.5 & 26791 & 38.5 & 26791 & 21.5 \\
\hline & \multicolumn{2}{|c|}{ Psychosocial health* } & \multicolumn{2}{|l|}{ Obesity* } & \multicolumn{2}{|c|}{ Smokingt } \\
\hline & \multicolumn{2}{|c|}{$\begin{array}{l}(=1 \text { if } S D Q \geq 17 \text { for ages } \\
4-15 \text { or if } G H Q-12 \geq 4 \text { for } \\
\text { ages } 16+)\end{array}$} & \multicolumn{2}{|c|}{$\begin{array}{l}\text { (=1 according to IOTF } \\
\text { classification for ages } 2-17 \text { or } \\
\text { if } B M I \geq 30 \text { for ages } 18+\text { ) }\end{array}$} & \multicolumn{2}{|c|}{$\begin{array}{l}\text { (=1 if currently smokes } \\
\text { for ages } 8+\text { ) }\end{array}$} \\
\hline Age group (years) & Sample & $\%$ & Sample & $\%$ & Sample & $\%$ \\
\hline $0-11^{*}$ & 1651 & 7.3 & 3020 & 7.9 & \multirow{2}{*}{2646} & \multirow{2}{*}{3.2} \\
\hline $12-15 t$ & 803 & 7.7 & 1246 & 6.7 & & \\
\hline 16-19 & 1100 & 16.5 & 1107 & 9.4 & 1202 & 23.1 \\
\hline $20-24$ & 1264 & 16.7 & 1303 & 16.0 & 1521 & 28.7 \\
\hline $25-44$ & 7492 & 14.1 & 7661 & 21.9 & 9008 & 24.0 \\
\hline $45-64$ & 7426 & 16.7 & 7732 & 29.5 & 8904 & 20.1 \\
\hline $65+$ & 5193 & 14.0 & 4855 & 30.5 & 6424 & 10.3 \\
\hline All & 24929 & 13.7 & 26924 & 21.9 & 29705 & 18.6 \\
\hline
\end{tabular}

The fact that equalisation may occur later than originally theorised has important implications, particularly in regards to the mechanisms driving the process of equalisation. West's seminal 1997 paper links equalisation with the transition to and from secondary school. ${ }^{4}$ Our results suggest that equalisation is unlikely to stem from direct effects of secondary school such as health-promoting resources and homogeneous school environments across social strata. However, other aspects of adolescence which may be related to, but not dependent on, the transition to secondary school may be subject to cohort effects which could cause shifts in the typical periods of equality. West emphasises the importance of increasing peer group influence on health and health behaviours. A delay in the increase of peer group influences may lead to a corresponding delay in equalisation.

This is also related to other aspects of adolescence which West cites as potential mechanisms for equalisation. Increasing time with peers may be associated with less time in the family home reducing the influence of the home environment including socially gradated exposures to 'domestic pollutants', secondhand smoke or family influenced health behaviours. ${ }^{4}$ Furthermore, increasing time with peers may be associated with the initiation of health-risk behaviours. ${ }^{27} 28$ In the UK and throughout Europe, substance initiation in early/midadolescence is declining. ${ }^{29} 30$ This trend may be related to a delayed onset of equalisation, given the importance that West and others place on peer-influenced health-risk behaviours for the onset of equalisation.

While equalisation has been linked with the commencement of secondary school, the re-emergence of inequalities is not tied to any specific life-course event. Rather, it is associated with the onset of adulthood, a concept which is intrinsically individually variable. As such, the re-emergence of inequality varies in response to culture, context and the health variable in question. There has been growing research interest in the changing nature of the transition from adolescence to adulthood. The concept of 'emerging adulthood' has gained credence to conceptualise the protracted transition to adulthood across Western cultural contexts. ${ }^{15}$ Research regarding the timing of key life events that are culturally salient in the definition of adulthood, including moving out, marriage, career progression, cohabitation and parenthood has led to conclusions that the transition to adulthood has recently shifted from a 'early, contracted and simple' process to one which is 'late, protracted and complex'. 31 32 If, as suggested, the re-emergence of inequalities is driven by the adult roles, environments and behaviours by which health inequalities are produced, then as West claimed, 'given the changing nature of the youth-adult transition, the age at which health inequalities 're-emerge' is likely to vary' (ref. 4, p. 852).

Evidence for the re-emergence of health inequalities across adulthood was stronger in females than in males. This may be because the extents of health inequalities are larger in adult females, despite similar levels of inequalities in adolescence. In other words, when inequalities re-emerge in adulthood, they do so more strongly for females. Though the findings regarding gender differences in health inequalities are mixed, there have been some suggestions that socioeconomic status, particularly level of education, is more strongly associated with health in females. $^{33}{ }^{34}$ Education appears to have a stronger link with health for females because it confers advantages in adulthood, 
Table 3 Income-related inequality in health and health-related behaviour by age group and gender

\begin{tabular}{|c|c|c|c|c|c|c|}
\hline \multicolumn{4}{|l|}{ Males } & \multicolumn{3}{|l|}{ Females } \\
\hline Age & $\mathrm{CCl}$ & PCCl† & ME income $\ddagger$ & $\mathrm{CCl}$ & PCCl† & ME income $\ddagger$ \\
\hline \multicolumn{7}{|c|}{ General Health } \\
\hline $0-11$ & $-0.0565^{* * *}$ & -0.0388 & $-0.0230^{* * *}$ & $-0.0600^{* * *}$ & -0.0412 & $-0.0241^{* * *}$ \\
\hline $12-15$ & $-0.0523^{* * *}$ & -0.0506 & $-0.0304(0.4)^{* * *}$ & $-0.0635^{* * *}$ & -0.0546 & $-0.0321(0.7)^{* * *}$ \\
\hline $16-19$ & $-0.0658^{* * *}$ & -0.0343 & $-0.0182(0.03)^{* *}$ & $-0.1463^{* * *}$ & -0.0791 & $-0.0419(0.5)^{* * *}$ \\
\hline $20-24$ & $-0.0952^{* * *}$ & -0.0852 & $-0.0457(0.13)^{* * *}$ & $-0.1184^{* * *}$ & -0.0575 & $-0.0310(0.19)^{* * *}$ \\
\hline $25-44$ & $-0.1739^{* * *}$ & -0.1304 & $-0.0726(0.07)^{* * *}$ & $-0.2028^{* * *}$ & -0.1557 & $-0.0844(<0.001)^{* * *}$ \\
\hline $45-64$ & $-0.3066^{* * *}$ & -0.2673 & $-0.1506(0.04)^{* * *}$ & $-0.3015^{* * *}$ & -0.2747 & $-0.1577(<0.001)^{* * *}$ \\
\hline $65+$ & $-0.2306^{* * *}$ & -0.1282 & $-0.0770(<0.001)^{* * *}$ & $-0.1859^{* * *}$ & -0.0948 & $-0.0604(<0.001)^{* * *}$ \\
\hline All & $-0.1883^{* * *}$ & -0.1370 & $-0.0751 * * *$ & $-0.2127^{* * *}$ & -0.1456 & $-0.0808^{* * *}$ \\
\hline \multicolumn{7}{|c|}{ Longstanding illness } \\
\hline $0-11$ & $-0.0567^{* * *}$ & -0.0404 & $-0.0239 * *$ & $-0.0312^{* *}$ & -0.0260 & $-0.0153^{*}$ \\
\hline $12-15$ & $-0.0552^{* *}$ & -0.0497 & $-0.0298(0.8)^{*}$ & $-0.0766^{* * *}$ & -0.0787 & $-0.0470(0.13)^{* * *}$ \\
\hline $16-19$ & 0.0019 & -0.0088 & $-0.0046(0.3)$ & -0.0320 & -0.0369 & $-0.0195(0.2)$ \\
\hline $20-24$ & -0.0488 & -0.0496 & $-0.0267(0.2)^{*}$ & $-0.0539^{*}$ & -0.0258 & $-0.0140(0.6)$ \\
\hline $25-44$ & $-0.1108^{* * *}$ & -0.1052 & $-0.0590(0.3)^{* * *}$ & $-0.1207^{* * *}$ & -0.1071 & $-0.0579(0.02)^{* * *}$ \\
\hline $45-64$ & $-0.1991^{* * *}$ & -0.1832 & $-0.1012(0.02)^{* * *}$ & $-0.2031^{* * *}$ & -0.1793 & $-0.1030(0.004)^{* * *}$ \\
\hline $65+$ & $-0.0801^{* * *}$ & -0.0470 & $-0.0279(<0.001)^{* * *}$ & $-0.0611^{* * *}$ & -0.0198 & $-0.0125(<0.001)$ \\
\hline All & $-0.1247^{* * *}$ & -0.1074 & $-0.0586^{\star * *}$ & $-0.1355^{* * *}$ & -0.0976 & $-0.0541^{* * *}$ \\
\hline \multicolumn{7}{|c|}{ Limiting longstanding illness } \\
\hline $0-11$ & $-0.0484^{* * *}$ & -0.0338 & $-0.0201^{* * *}$ & $-0.0330^{* * *}$ & -0.0273 & $-0.0161^{* * *}$ \\
\hline $12-15$ & $-0.0365^{*}$ & -0.0266 & $-0.0160(0.7)$ & $-0.0607^{* * *}$ & -0.0573 & $-0.0343(0.2)^{* * *}$ \\
\hline $16-19$ & -0.0302 & -0.0221 & $-0.0116(0.7)^{*}$ & $-0.0548^{* *}$ & -0.0470 & $-0.0248(0.2)^{* * *}$ \\
\hline $20-24$ & $-0.0430^{*}$ & -0.0400 & $-0.0215(0.4)^{* * *}$ & $-0.0585^{* *}$ & -0.0282 & $-0.0153(0.4)$ \\
\hline $25-44$ & $-0.1400^{* * *}$ & -0.1006 & $-0.0565(0.2)^{* \star *}$ & $-0.1332^{* * *}$ & -0.1016 & $-0.0550(0.006)^{* * *}$ \\
\hline $45-64$ & $-0.2648^{* * *}$ & -0.2058 & $-0.1136(0.07)^{* * *}$ & $-0.2279^{* * *}$ & -0.1944 & $-0.1117(0.01)^{* * *}$ \\
\hline $65+$ & $-0.1719^{* * *}$ & -0.0972 & $-0.0577(<0.001)$ & $-0.1089^{* * *}$ & -0.0429 & $-0.0270(<0.001)^{* * *}$ \\
\hline All & $-0.1570^{* * *}$ & -0.1060 & $-0.0578^{* * *}$ & $-0.1557^{* * *}$ & -0.0974 & $-0.0540^{* * *}$ \\
\hline \multicolumn{7}{|c|}{ Psychosocial wellbeing } \\
\hline $4-11$ & $-0.1232^{* * *}$ & -0.1099 & $-0.0654^{* * *}$ & $-0.1070^{* * *}$ & -0.0765 & $-0.0464^{* * *}$ \\
\hline $12-15$ & $-0.0884^{* * *}$ & -0.0710 & $-0.0426(0.2)^{\star * *}$ & $-0.0753^{* * *}$ & -0.0713 & $-0.0438(0.8)^{* * *}$ \\
\hline $16-19$ & -0.0295 & -0.0262 & $-0.0139(0.11)^{*}$ & -0.0187 & -0.0151 & $-0.0080(<0.001)$ \\
\hline $20-24$ & $-0.0673^{* *}$ & -0.0618 & $-0.0342(0.3)^{* \star *}$ & $-0.0537^{* *}$ & -0.0397 & $-0.0215(0.16)^{\star *}$ \\
\hline $25-44$ & $-0.0805^{* * *}$ & -0.0586 & $-0.0327(0.8)^{* * *}$ & $-0.0886^{* * *}$ & -0.0683 & $-0.0372(0.15)^{* * *}$ \\
\hline $45-64$ & $-0.1420^{* * *}$ & -0.0875 & $-0.0485(0.06)^{* * *}$ & $-0.1303^{* * *}$ & -0.0996 & $-0.0577(0.04)^{* * *}$ \\
\hline $65+$ & $-0.0772^{* * *}$ & -0.0248 & $-0.0148(<0.001)^{* * *}$ & $-0.0320^{* * *}$ & -0.0169 & $-0.0107(<0.001)^{* *}$ \\
\hline All & $-0.0705^{* * *}$ & -0.0483 & $-0.0264^{* * *}$ & $-0.0663^{* * *}$ & -0.0558 & $-0.0311 * * *$ \\
\hline \multicolumn{7}{|l|}{ Obesity } \\
\hline $0-11$ & $-0.0406^{* * *}$ & -0.0292 & $-0.0172^{* * *}$ & $-0.0611^{* * *}$ & -0.0439 & $-0.0260^{* * *}$ \\
\hline $12-15$ & $-0.0685^{* * *}$ & -0.0591 & $-0.0354(0.5)^{* * *}$ & $-0.0532^{* * *}$ & -0.0308 & $-0.0181(0.5)^{* *}$ \\
\hline $16-19$ & 0.0028 & -0.0102 & $-0.0056(0.17)$ & $-0.0447^{* *}$ & -0.0135 & $-0.0074(0.11)$ \\
\hline $20-24$ & 0.0169 & 0.0098 & $0.0053(0.3)$ & -0.0363 & -0.0237 & $-0.0126(0.9)$ \\
\hline $25-44$ & $-0.0400^{* * *}$ & -0.0216 & $-0.0124(0.3)^{*}$ & $-0.1441^{* * *}$ & -0.1109 & $-0.0610(0.004)^{* * *}$ \\
\hline $45-64$ & -0.0147 & -0.0069 & $-0.0038(0.3)$ & $-0.1237^{* * *}$ & -0.0889 & $-0.0524(0.14)^{* * *}$ \\
\hline $65+$ & $-0.0446^{* * *}$ & -0.0319 & $-0.0202(0.16)^{* *}$ & $-0.0453^{* * *}$ & -0.0455 & $-0.0307(0.12)^{* * *}$ \\
\hline All & 0.0062 & -0.0455 & $-0.0307^{* * *}$ & $-0.0838^{* * *}$ & -0.0737 & $-0.0419^{* * *}$ \\
\hline \multicolumn{7}{|l|}{ Smoking } \\
\hline $7-15$ & $-0.0190^{* * *}$ & -0.0041 & $-0.0024^{* * *}$ & $-0.0263^{* * *}$ & -0.0064 & $-0.0038^{* * *}$ \\
\hline $16-19$ & $-0.1252^{* * *}$ & -0.0897 & $-0.0473(0.3)^{* * *}$ & $-0.1682^{* * *}$ & -0.1251 & $-0.0657(0.5)^{\star * *}$ \\
\hline $20-24$ & $-0.1256^{* * *}$ & -0.1404 & $-0.0754(0.9)^{\star \star *}$ & $-0.1382^{* * *}$ & -0.0949 & $-0.0519(0.9)^{* * *}$ \\
\hline $25-44$ & $-0.2181^{* * *}$ & -0.1971 & $-0.1107(0.3)^{* * *}$ & $-0.2349^{* * *}$ & -0.2198 & $-0.1192(0.02)^{* * *}$ \\
\hline $45-64$ & $-0.1883^{* * *}$ & -0.1625 & $-0.0897(0.5)^{* * *}$ & $-0.1607^{* * *}$ & -0.1307 & $-0.0750(0.01)$ \\
\hline $65+$ & $-0.0915^{* * *}$ & -0.0494 & $-0.0297(<0.001)^{* * *}$ & $-0.0437^{* * *}$ & -0.0300 & $-0.0191(<0.001)^{* * *}$ \\
\hline All & $-0.1107^{* * *}$ & -0.1335 & $-0.0727^{* * *}$ & $-0.1234^{* * *}$ & -0.1328 & $-0.0737^{* * *}$ \\
\hline
\end{tabular}

${ }^{* * *} \mathrm{p}<0.001 ;{ }^{* *} \mathrm{p}<0.05 ;{ }^{*} \mathrm{p}<0.1$.

tNo statistical inference for the PCCls is reported. Calculating standard errors around PCCls would require applying bootstrapping methods on the 96 estimates provided in this study. \#Numbers in brackets indicate $\mathrm{p}$ value for the statistical test that the income effect is different to the effect on the previous age group.

CCl, Corrected Concentration Index; GHQ, General Health Questionnaire; ME, Marginal Effect; PCCI, Partial Corrected Concentration Index; SDQ, Strengths and Difficulties Questionnaire. 
including psychosocial resources ${ }^{35}$ and preferable working conditions $^{36}$ that are more strongly linked with health in females than for males. As such, inequalities may emerge more strongly for women in adulthood despite similar levels in childhood and adolescence. $^{37}$

Our results, despite suggesting a short-term reduction in health inequalities, clearly point to a continuing trend of lifelong inequalities across health domains. Equalisation is only short-term and it is unclear that this confers any long-lasting benefits. Inequalities subsequently re-emerge stronger than at any point previously and grow in magnitude until retirement age. As such, it is important for public policy to continue to focus on reducing health inequalities across the life-span, and that any equalisation in adolescents does not become a smokescreen to a pervasive problem.

However, the findings do suggest that the health inequalities bestowed by early-life SES can be at least partially overridden by other factors including peer and school effects. Since inequalities re-emerge during the transition period into employment during late adolescence and early adulthood when earlier SES-related factors supersede those with drove equalisation, a key policy focus should be on facilitating this transition. This may include improving educational and occupational opportunities throughout early adulthood and continued access to health resources beyond secondary school. Relatedly, improving the transition from adolescent health services to adult services could feasibly attenuate the re-emergence of health inequalities. ${ }^{38}$ If positive influences driving equalisation can be sustained and serve as protective factors into mid-adulthood, this could lead to a general improvement in health across the social gradient and a longer-term reduction of health inequalities. However, achieving such aims requires an enhanced understanding of the mechanisms of the initiation of a period of equalisation as well as the re-emergence of inequalities in adulthood.

Several limitations warrant mention. The data are crosssectional so we cannot rule out cohort effects. Due to the nature of the research question, longitudinal data would provide a better estimation of stability of inequalities across the lifespan. Most measures rely on self-reported data, and past research suggests under-reporting and over-reporting in adolescent health measures. ${ }^{39}$ Furthermore, some health measures are not consistent across age groups, for example, our measures of psychosocial distress, and it is unclear that these measures are directly comparable. Relatedly, reporting for some measures switches from parent-report to self-report raising similar issues of comparability. ${ }^{40}$

Further research should include a wider array of health measures as equalisation periods may vary by outcome. There has also been criticism of the dependence on household income as a proxy for SES in past studies of equalisation with some work attempting to replicate the findings using other proxies including parent education or occupation or self-reported academic achievement. ${ }^{8} 941$ Finally, considering our results have highlighted inconsistencies in the timing of the period of equalisation, the research would have benefitted from finer-grained measures of age rather than using age groups spanning several years. Using large age groups makes it difficult to determine the age at which inequalities diminish and re-merge.

Our work shows that inequalities occur across the life-course but suggest a period of equalisation in some indicators in late adolescence and early adulthood, particularly for males. Inequalities then tend to re-emerge at greater magnitude than at any earlier period in the life-course. The equalisation period does not map onto the timing of adolescence or secondary school. This highlights the evolving nature of the youth-adult transition, and might suggest that some of the hypothesised mechanisms, such as direct secondary school effects are either less important than once thought or that there is a lag before their effects are reflected in the reduction and re-emergence of health inequalities.

\section{What is already known in this subject}

A growing body of research suggests that, despite generally pervasive health inequalities across the lifespan, health inequalities are attenuated in adolescence. The existing literature has investigated the equalisation hypothesis by examining socioeconomic effects at different time points throughout adolescence, or by interpreting the effect on health outcomes of age and socioeconomic status interactions. However, we are aware of no published attempts to systematically examine changes in inequalities across a wide range of ages.

\section{What this study adds}

In this study, we found marked socioeconomic-related health inequality in childhood, and some evidence of equalisation in late adolescence and early adulthood in some health indicators, with inequality re-emerging again in mid-adulthood and late adulthood. Our results also indicate that equalisation may occur later than originally theorised. The findings suggest that the transition period during late adolescence and early adulthood should be a key policy focus.

Acknowledgements LV-T would like to acknowledge the IMBRAIN project (FP7-REGPOT-2012-CT2012-31637-IMBRAIN), funded under the 7th Framework Programme (Capacities).

Contributors LV-T was involved in the conception and design, analysis and interpretation of data, in drafting the article and has approved the submitted version. She is also responsible for the overall content as guarantor(s). DH was involved in the conception and design, analysis and interpretation of data, in drafting the article and has approved the submitted version. SM was involved in the conception and design, analysis and interpretation of data, in drafting the article and has approved the submitted version. RMV was involved in the conception and design, analysis and interpretation of data, in drafting the article and has approved the submitted version.

Funding This is an independent report commissioned and funded by the Policy Research Programme in the Department of Health. The views expressed are not necessarily those of the Department.

\section{Competing interests None.}

Provenance and peer review Not commissioned; externally peer reviewed.

Open Access This is an Open Access article distributed in accordance with the Creative Commons Attribution Non Commercial (CC BY-NC 3.0) license, which permits others to distribute, remix, adapt, build upon this work non-commercially, and license their derivative works on different terms, provided the original work is properly cited and the use is non-commercial. See: http://creativecommons.org/ licenses/by-nc/3.0/

\section{REFERENCES}

1 Swift R. The relationship between health and GDP in OECD countries in the very long run. Health Econ 2011;20:306-22.

2 Viner RM, Ozer EM, Denny $\mathrm{S}$, et al. Adolescence and the social determinants of health. Lancet 2012;379:1641-52. 
3 Marmot M. Fair society, healthy lives: the Marmot review. London: University College London, 2010.

4 West P. Health inequalities in the early years: is there equalisation in youth? Soc Sci Med 1997;44:833-58.

5 Blane D, Bartley M, Smith GD, et al. Social patterning of medical mortality in youth and early adulthood. Soc Sci Med 1994;39:361-6.

6 Dibben C, Popham F. Are health inequalities evident at all ages? An ecological study of English mortality records. Eur J Public Health 2013;23:39-45.

7 Green MA. The equalisation hypothesis and changes in geographical inequalities of age based mortality in England, 2002-2004 to 2008-2010. Soc Sci Med 2013;87:93-8

8 Spencer NJ. Social equalisation in youth: evidence from a cross-sectional British survey. Eur J Public Health 2006;16:368-75.

9 West $P$, Sweeting $H$, Leyland $A H$. School effects on pupils' health behaviours: Evidence in support of the health promoting school. Res Pap Educ 2004;19:261-91.

10 Wickrama KAS, Noh S, Elder GH. An investigation of family SES-based inequalities in depressive symptoms from early adolescence to emerging adulthood. Adv Life Course Res 2009;14:147-61.

11 Currie C, Gabhainn SN, Godeau E, et al. Inequalities in young people's health. HBSC international report from the 2005/2006 survey. Copenhagen: WHO Europe, 2008.

12 Hale DR, Viner RM. Policy responses to multiple risk behaviours in adolescents. J Public Health 2012;34(Suppl 1):i11-19.

13 Gardner M, Steinber L. Peer influence on risk taking, risk preference, and risky decision making in adolescence and adulthood: an experimental study. Dev Psychol 2005;41:625-35.

14 World Health Organization. Adolescent development. http://www.who.int/maternal_ child_adolescent/topics/adolescence/dev/en/ (accessed 26 Nov 2013).

15 Arnett JJ. Emerging adulthood. A theory of development from the late teens through the twenties. Am Psychol 2000;55:469-80.

16 World Health Organization. Definition of an older or elderly person. http://www. who.int/healthinfo/survey/ageingdefnolder/en/ (accessed 26 Nov 2013).

17 Goodman R. The Strengths and Difficulties Questionnaire: A research note. J Child Psychol Psychiatry 1997;38:581-6.

18 Goldberg D, Williams $P$. The users' guide to the general health questionnaire. Windsor, UK: NFER-Nelson, 1988.

19 Cole TJ, Bellizzi M, Flegal K, et al. Establishing a standard definition for child overweight and obesity worldwide: international survey. BMJ 2000;320:1240-5.

20 Cole TJ, Freeman JV, Preece MA. British 1990 growth reference centiles for weight, height, body mass index and head circumference fitted by maximum penalized likelihood. Stat Med 1998;17:407-29.

21 Wagstaff $A$, Paci $P$, van Doorslaer $E$. On the measurement of inequalities in health Soc Sci Med 1991;33:545-57.

22 Erreygers G. Correcting the concentration index. J Health Econ 2009:28:504-15.
23 Gravelle H, Sutton M. Income related inequalities in self assessed health in Britain: 1979-1995. J Epidemiol Community Health 2002;57:125-9.

24 Clogg CC, Petkova E, Haritou A. Statistical methods for comparing regression coefficients between models. AJS 1995;100:1261-312.

25 O'Donnell O, van Doorslaer E, Wagstaff A, et al. Analyzing Health Equity Using Household Survey Data. World Bank Publications, 2008.

26 StataCorp. Stata Statistical Software: Release 12. College Station, TX: StataCorp LP, 2011.

27 Kiesner J, Poulin F, Dishion TJ. Adolescent substance use with friends: moderating and mediating effects of parental monitoring and peer activity contexts. Merrill-Palmer Q (Wayne State University Press) 2010;56:529-56.

28 Goldstein SE, Davis-Kean PE, Eccles JS. Parents, peers, and problem behavior: a longitudinal investigation of the impact of relationship perceptions and characteristics on the development of adolescent problem behavior. Dev Psychol 2005:41:401-13

29 Hibell B, Guttormsson U, Ahlström S, et al. The 2011 ESPAD report: Substance use among students in 36 European countries. Stockholm, Sweden: The Swedish Council for Information on Alcohol and Other Drugs (CAN), 2011.

30 Hagell A, Coleman J, Brooks F. Key data on adolescence 2013. London: Association for Young People's Health, 2013.

31 Kins E, Beyers W. Failure to launch, failure to achieve criteria for adulthood? J Adolesc Res 2010;25:743-77.

32 Billari FC, Liefbroer AC. Towards a new pattern of transition to adulthood? Adv Life Course Res 2010;15:59-75.

33 Matthews S, Manor O, Power C. Social inequalities in health: are there gender differences? Soc Sci Med 1999;48:49-60.

34 Zhang Q, Wang Y. Socioeconomic inequality of obesity in the United States: do gender, age, and ethnicity matter? Soc Sci Med 2004;58:1171-80.

35 Thurston RC, Kubzansky LD, Kawachi I, et al. Is the association between socioeconomic position and coronary heart disease stronger in women than in men? Am J Epidemiol 2005;162:57-65.

36 Ross CE, Mirowsky J. Sex differences in the effect of education on depression: Resource multiplication or resource substitution? Soc Sci Med 2006;63: 1400-13.

37 Diaz MDM. Socio-economic health inequalities in Brazil: gender and age effects. Health Econ 2002;11:141-54.

38 Viner R. Transition from paediatric to adult care. Bridging the gaps or passing the buck? Arch Dis Child 1999:81:271-5.

39 Williams RJ, Nowatzki N. Validity of adolescent self-report of substance use. Subst Use Misuse 2005;40:1-13.

40 Collishaw S, Goodman R, Ford T, et al. How far are associations between child, family and community factors and child psychopathology informant-specific and informant-general? J Child Psychol Psychiatry 2009;50:571-80.

41 Hagquist CEI. Health inequalities among adolescents - the impact of academic orientation and parents' education. Eur J Public Health 2007:17:21-6. 